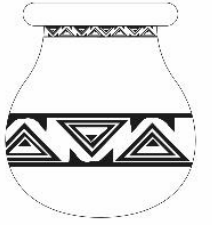

\title{
A FORMAÇÃO DO CIENTISTA NORMAL COMO UMA INICIAÇÃO DOGMÁTICA A UMA TRADIÇÃO PARADIGMÁTICA SEGUNDO KUHN
}

Gleyce Kelly da Luz Albuquerque ${ }^{1}$

Resumo: Neste artigo, meu objetivo é analisar de que maneira o cientista, no âmbito das Ciências Naturais, é educado para assimilar, aplicar e articular um determinado paradigma na solução dos problemas de ciência normal, sem colocá-lo (o paradigma) criticamente em questão, assim qualquer erro que venha a ocorrer na pesquisa é atribuído ao cientista e não ao paradigma. Pretendo também, mostrar que o caráter dogmático do paradigma não permite que o cientista desenvolva pesquisas visando novas descobertas que não se enquadrem nos parâmetros ditados pelo mesmo, tal atitude exige total aceitação e comprometimento da comunidade científica para com o paradigma aceito, gerando assim, uma espécie de profissão de fé na capacidade do paradigma em resolver os quebra-cabeças que se apresentam na prática da ciência normal.

Palavras-Chave: ciência normal, dogmatismo, paradigma, fé, educação.

${ }^{1}$ Graduada em Filosofia pela Universidade Federal do Pará (UFPA) e integrante do grupo de pesquisa "Filosofia da Ciência”, cadastrado no CNPQ e certificado pela UFPA. Trabalho orientado pela Prof ${ }^{a}$. Dra . Elizabeth de Assis Dias. 


\section{Introdução}

O objetivo do presente trabalho é analisar como se dá a formação do cientista para ser membro de uma comunidade científica. Pretendemos mostrar que essa formação tem caráter dogmático, na medida em que o cientista é educado para assimilar e reproduzir o paradigma aceito pelo grupo. Para esclarecer tal temática iremos mostrar, primeiramente, como no desenvolvimento de uma ciência se estabelece um paradigma como norteador das pesquisas de ciência normal, gerando uma tradição paradigmática e posteriormente, pretendemos esclarecer como o cientista é educado para ser membro dessa comunidade científica.

\section{O paradigma como norteador das pesquisas de ciência normal}

Kuhn considera que a ciência no decorrer de seu desenvolvimento passa por estágios característicos até atingir sua maturidade. Esses estágios são: pré-paradigmático (pré-ciência), paradigmático, crise, revolução científica e novo estágio paradigmático. Nossa análise irá se concentrar no período paradigmático, no qual os cientistas desenvolvem suas pesquisas à luz de um paradigma aceito pelo grupo e estabelece-se assim, a prática da ciência normal.

Na obra A Estrutura das Revoluções Científicas, Kuhn define a ciência normal como sendo uma "pesquisa que é firmemente baseada em realizações científicas que são reconhecidas por uma comunidade cientifica" (KUHN, 2013, p. 71). Para que essas pesquisas de ciência normal, próprias do estágio de maturidade se estabeleçam, a ciência precisa superar seu estágio de pré-ciência. O paradigma será o elemento que norteará e determinará a pesquisa científica quando a ciência atingir o estágio paradigmático.

No período pré-paradigmático, há uma multiplicidade de escolas e cada uma delas possui uma proposta teórica sobre os fundamentos de um campo de estudo, ou seja, cada uma possui um paradigma e por meio do debate e da persuasão tentam convencer os membros das escolas rivais de que seu paradigma é mais indicado para nortear a prática da ciência. A proposta que reunir o maior número de adeptos em torno dela de modo a gerar um consenso é a que passará a servir de parâmetro para as pesquisas a serem desenvolvidas. Estabelece-se assim, o período paradigmático, no qual predomina um único paradigma, consensualmente aceito pelo grupo, fazendo com que, a ciência normal seja realizada à luz de um paradigma. Afirma Kuhn:

Homens cuja pesquisa está baseada em paradigmas compartilhados estão comprometidos com as mesmas regras e padrões para a prática científica. Esse comprometimento e o consenso aparente que produz são pré-requisitos para a 


\section{REVISTA APOENA - Per. dos Dis. de Fil. da UFPA \\ Belém, 2019, V. 1, N.1.}

ciência normal, isto é, para a gênese e a continuação de uma tradição de pesquisa determinada. (KUHN, 2013, p. 72).

Os cientistas que desenvolvem as pesquisas de ciência normal compartilham o mesmo paradigma e estão comprometidos com as mesmas regras e padrões para a prática científica. Esse comprometimento e o consenso aparente que produz são pré-requisitos para a ciência normal, isto é, para a gênese e a continuação de uma tradição de pesquisa determinada. (KUHN, 2013, p. 72). Kuhn compreende por paradigma uma "realização científica universalmente reconhecida que, durante muito tempo, fornecem problemas e soluções modelares para uma comunidade de praticantes de uma ciência" (KUHN, 2013, p. 53). A ciência normal, de posse de um paradigma procura solucionar os problemas que se apresentam seguindo seus modelos exemplares de solução. Kuhn compara os problemas de ciência normal a quebra-cabeças, pois estes desafiam o cientista e testam sua engenhosidade na resolução dos mesmos e só a falta de habilidade do cientista o impedirá de solucioná-los, uma vez que o modelo de solução já está dado pelo paradigma, o cientista apenas o aplica na solução dos problemas. Nessa pratica da ciência normal não cabe ao cientista por em questão ou criticar o paradigma.

Todavia, como o paradigma não é posto em questão, qualquer falha na pesquisa nunca será atribuída ao mesmo, mas sim ao cientista que não soube aplicá-lo corretamente. Além do cientista normal não poder criticar o paradigma, ele também não visa novas descobertas, pois buscar soluções para os problemas, fora do âmbito do paradigma são estritamente proibidas na ciência normal, logo, para que a prática da ciência normal seja bem sucedida o paradigma deve ser seguido de forma rigorosa. O paradigma funciona assim, como uma espécie de dogma norteador da prática da ciência normal, pois cabe a ela apenas aplicar, ajustar e precisar o paradigma, mas nunca se poderá questioná-lo ou duvidar de sua eficácia na solução dos problemas.

Esse caráter dogmático do paradigma fica ainda mais evidente quando Kuhn considera que no processo de escolha de um paradigma os cientistas recorrem a fé. A esse respeito no artigo A Função do Dogma na Investigação Científica, Kuhn diz que "uma decisão desse tipo só pode ser feita com base na fé" (KUHN 2013, p. 258). Essa fé se traduz em crença em seu sucesso, em sua eficácia. Eles acreditam que ele será bem sucedido, por isso, não levantam dúvidas sobre seus supostos méritos.

Kuhn considera que, na ciência, os dogmas são indispensáveis para que ela possa se desenvolver. O dogmatismo é, assim, uma forte característica do desenvolvimento científico consolidado, ou seja, do período paradigmático em que a aceitação do paradigma implica em 
compromissos compartilhados pelo grupo. Esses cientistas que comungam um mesmo paradigma criam uma tradição em torno dele e para que essa tradição tenha continuidade, fazse necessário a incorporação de novos adeptos à mesma. Assim, os estudantes que iniciam sua formação nos cursos superiores são desde cedo educados para seguir determinada tradição paradigmática. Iremos apresentar a seguir como o estudante é educado para aceitar e assimilar um paradigma de modo a dar continuidade a uma determinada tradição paradigmática.

\section{A formação do cientista para seguir uma determinada tradição paradigmática}

Ao tratar da formação dos estudantes para seguirem uma determinada tradição paradigmática, Kuhn se refere, em particular, aos da área das ciências naturais, pois é justamente nessas áreas que ele considera que há paradigmas consolidados. Então, como é repassado esses paradigmas as novas gerações? Essa formação é feita com base em manuais de vulgarização cientifica, ou seja, manuais que visam iniciar os leigos nos conhecimentos de alguma ciência. Esses manuais geralmente apresentam as teorias científicas mais atuais com as quais o estudante se defronta em sua formação e por meio deles se familiarizam com o aparato conceitual, os problemas mais comuns e os modelos de solução para estes que são estudados pela comunidade cientifica na qual irá futuramente ingressar. Esses manuais são, assim, instrumentos fundamentais para a formação de uma nova geração de cientistas que irão compor as comunidades científicas regidas por paradigmas.

Podemos dizer que por meio desses manuais os estudantes são treinados para assimilar e aplicar um paradigma, na medida em que seu trabalho futuro como praticante da ciência normal consistirá nessa tarefa.

Um exemplo, que ilustra como se dá essa assimilação do aparato conceitual do paradigma, que podemos citar, diz respeito a terminologia Newtoniana, os estudantes precisam assimilar os termos adequados para se referirem aos objetos da física e seus lugares no espaço e no tempo, ou seja, antes deles adentrarem em determinados assuntos mais específicos, terão que assimilar um vocabulário suficiente para permitir uma descrição no decorrer das trajetórias e análises das velocidades e acelerações dos corpos. Essa assimilação funciona, portanto, como um pré-requisito para que a referida descrição quantitativa seja realizada de forma adequada pelos iniciados. Assim os estudantes são educados para assimilar e aplicar o paradigma sem questioná-lo ou criticá-lo, limitando-se apenas a reproduzi-lo para a solução dos problemas enfrentados e é nesse sentido que a educação do cientista é dogmática. 
É importante ressaltar que os futuros cientistas não estudam as obras fontes ou clássicas de sua área como a Física de Aristóteles, o Almagesto de Ptolomeu, os Principia e a Optica de Newton, a Eletricidade de Franklin, a Química de Lavoisier e a Geologia de Lyell (KUHN, 2013, p. 71) conhecem, por meio dos manuais, apenas, as teoria científicas que precisam aprender para praticar seu oficio, pois seu treino maior é na aplicação da teoria na solução de problemas. Por isso que as aplicações não estão nos manuais como um mero adorno, mas sim para mostrar que o processo de aprendizado de uma teoria depende do estudo de suas aplicações, incluindo-se aí a prática na resolução de problemas à luz do paradigma vigente:

Se, por exemplo, o estudioso da dinâmica newtoniana descobrir o significado de termos como força, massa, espaço e tempo, será menos porque utilizou as definições incompletas (embora muitas vezes úteis) do seu manual, do que por ter observado e participado da aplicação desses conceitos à resolução de problemas (KUHN, 2013, p. 120).

Dessa maneira, o emprego prático dos modelos na resolução dos quebra-cabeças é o que habilita os estudantes para o exercício da sua profissão. Desse modo, o conhecimento científico seria absorvido de uma maneira mais tácita do que explícita em uma comunidade científica regida por um paradigma, ou seja, os estudantes têm acesso aos modelos, mas não à compreensão do conhecimento e dos princípios que os fundamentam. São assim, formados para serem cientistas não críticos que aceitam os dogmas dominantes sem contestação. Dogma esse que, segundo Kuhn, é uma fonte de controvérsia, mas também "um instrumento inestimável que faz das ciências a atividade humana mais consistentemente revolucionária." (KUHN, 2012, p. 25).

\section{Considerações Finais}

Procuramos mostrar como a prática da ciência normal, norteada por um paradigma, é de certa forma dogmática, na medida em que implica em compromisso e aceitação de regras para o desenvolvimento das pesquisas, segundo os parâmetros estabelecidos pelo paradigma. Nas pesquisas de ciência normal não há lugar para critica, na medida em que o trabalho do cientista é reproduzir o paradigma.

Com relação a formação do candidato a cientista procuramos mostrar como ele é formado por meio de manuais de divulgação cientifica para assimilar um paradigma e aplicálo. Desta forma, a formação do cientista é uma iniciação dogmática a uma tradição preestabelecida de resolver problemas cujo modelo de solução está dado pelo paradigma. 


\section{BIBLIOGRAFIA}

ALVES, Francismary. Historiografia da Revolução Científica: Alexandre Koyré, Thomas Kuhn e Steven Shapin. Belo Horizonte, 2010.

KUHN, Thomas. A Estrutura das Revoluções Científicas. São Paulo: Editora Perspectiva S. A., 2013.

. A Função do Paradigma na Investigação Científica. Curitiba, 2012.

. On Learning Physics, in Thomas Kuhn and science education. Science \& education, Pittsburgh, Pensilvânia, n.9: p.11-19, January, 2000.

MOURA, Mauricio. A educação científica baseada em paradigmas: uma investigação sobre a filosofia Kuhniana. Salvador, 2008.

PORTOCARRERO, V., org. Filosofia, História e Sociologia das ciências I: abordagens contemporâneas [online]. Rio de Janeiro: Editora FIOCRUZ, 1994. 